\title{
THE NORMAL VASCULAR ANATOMY OF THE FEMORAL HEAD IN ADULT MAN
}

\author{
J. Trteta and M. H. M. Harrison, Oxford, Exglaxi) \\ From the Nuffield Orthopaedic Centre, Oxford
}

This paper gives an account of an investigation into the normal vascular anatomy of the adult femoral head. The work was undertaken to supply control material for research into the vascular changes accompanying osteoarthritis of the hip joint, and for this reason no account is given here of the conditions existing in the two decades preceding maturity. These will be presented on another occasion. Similarly we have not detailed the extra-articular course and anatomical variations of the arteries supplying the femoral head; they have been fully described by others. We shall commence our description of the vessels from where they are about to enter the bone, precisely the point at which the available information grows increasingly scanty; here they begin their physiological role, their function as conducting channels now having been fulfilled.

\section{HISTORICAL REVIEW}

In the past this subject has been approached by two different types of investigators; one group, comprising mainly surgeons and anatomists, successfully identified the arteries bringing blood to the upper end of the femur but were less interested in determining the fate of these vessels within the bone. A second group, constituted by pathologists and haematologists, were concerned with the structure and arrangement of the finest vessels within the bone mainly in relationship to haemopoiesis.

Palletta (1820), Cooper (1823), Sappey (1869) and Langer (1876) were among the nineteenth century workers who studied the vessels bringing blood into the upper end of the femur; they were followed in more recent years by Lexer et al. (1904), Nussbaum (1924), Kolodny (1925), Logròscino (1934), Vereby (1942), Wolcott (1943), Tucker (1949) and Howe et al. (19)50). Some of the most outstanding of the early contributions to the anatomical knowledge of the finer vessels within the bone were by Neumann (1869), Langer (1876), Rindfleisch (1880) and Van der Stricht (1892); later workers included Doan (1922 and 1925) and Drinker (192:2) and their associates. In studies devoted to the larger vessels, once the main arterial pathways had been identified further reports tended to centre on discussion whether, during growth, the epiphysial plate constitutes an absolute barrier to the circulations of epiphysis and metaphysis and also what arterial contribution to the blood supply of the femoral head, if any, is brought by the artery of the ligamentum teres. Parallel discussions have concerned the anatomy of the small vessels, as to whether the capillary circulation of the marrow is partly an open, or is a closed system.

No elucidation of either of these artificially separated problems has been achieved by this dual approach, and consequently our knowledge of the complete circulatory anatomy within human bone in general and this region of constant orthopaedic interest in particular is seriously deficient.

\section{DEFINITIONS AND NOMENCLATURE}

Throughout this article the term epiphysis is applied to that part of the head of the femur formed from the secondary centre of ossification. During the growth period the extent of the epiphysis is made obvious by the growth plate which limits it infero-laterally (Fig. 1), and in adult life a distinction continues in that the so-called epiphysial scar serves as a guide 


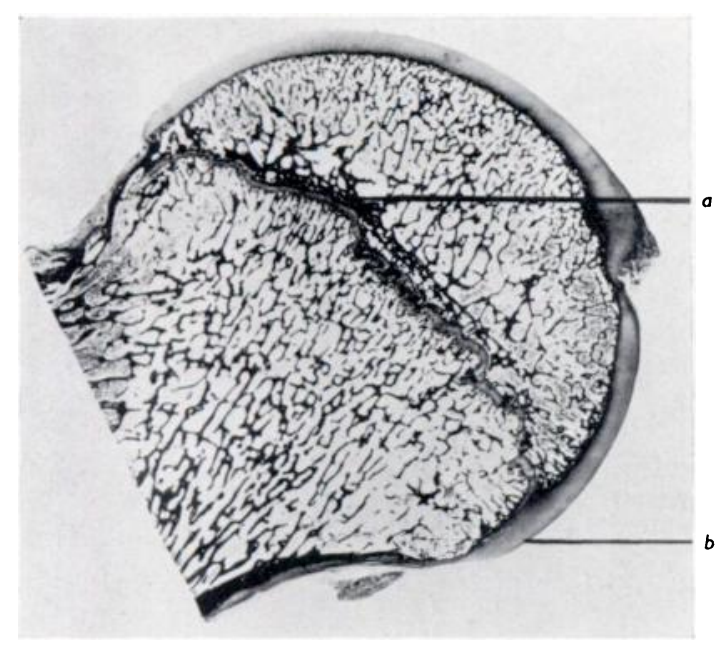

ligi. I

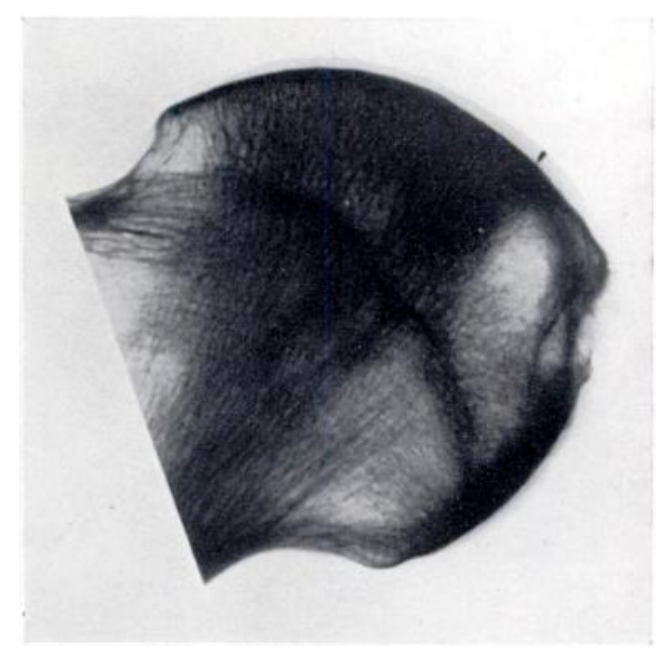

Fig. 2

Figure 1-Ihotomicrograph of a coronal section of a femoral head of a subject aged fourteen. a-Concentration of bone lamellae superficial to the epiphysial plate. b-Articular cartilage covering metaphysial bone $(\cdot 1 \cdot 2)$. Figure 2-Slab radiograph, coronal plane, from the femoral head of a subject aged seventy-two. A radio-opaque zone, the "epiphysial scar," is seen to occupy a position close to that which the epiphysial plate did during the years of growth.

to the position which the growth plate previously occupied (Fig. 2). We have observed that the system of lamellar bone which constitutes the scar lies close to, but on the epiphysial side of the growth cartilage, and the scar does not represent a zone of intense ossification produced within the plate at the time of synostosis. It will be seen in Figures 1 and 2 that the upper femoral epiphysis does not form the whole of the femoral head either during or after the growth period; at both times the proximal part of the diaphysis, the metaphysis, forms a substantial part of the head and is covered by articular cartilage (b, Fig. 1).

\section{MATERIALS AND METHODS}

This study has been made exclusively on human specimens obtained after death. I)ue to certain factors as yet beyond control (agonal vasospasm, post-mortem intravascular clotting) there is a fortuitous element inherent in any attempt to fill the vascular tree, post-mortem, with

TABI.E I

Age Distribution of the INjectei)

Material Suitable for Axalysis

(Thirty-six specimens)

\begin{tabular}{|cc|}
\hline $\begin{array}{c}\text { Age of subject at } \\
\text { time of death } \\
\text { (vears) }\end{array}$ & $\begin{array}{c}\text { Number of } \\
\text { femoral } \\
\text { heads }\end{array}$ \\
\hline $20-30$ & 2 \\
$31-40$ & 2 \\
$41-50$ & 1 \\
$51-60$ & 1 \\
$61-70$ & 12 \\
$71-80$ & 11 \\
$81-90$ & 5 \\
$91-100$ & 2 \\
\hline
\end{tabular}

contrast media and this has necessitated very many more injections than are reported here, the uninformative results being excluded from this paper. The material available for the analysis on which this report is based is shown in Table $I$.

vol. 35 B, No. 3, ACGUST 1953 
The techniques used to visualise the blood vessets within the bone are based on those previously described in the investigation of another circulatory problem (Trueta et al. 1947). The arteries that supply the upper end of the femur have been injected with various materials: in most instances the injections have been given into the medial femoral circumflex artery, but the common iliac and common femoral arteries have also been used. When injecting a suitably excised specimen one can obstruct branches which might otherwise divert the injection mass away from the upper end of the femur. No attempt has been made to estimate the actual injection pressures used, because the pressure recorded in the syringe or nearby artery is no indication of the effective injection pressure in the vessels as they enter the bone.

The injection masses used in this study were barium sulphate suspensions (Ardran 1953), 10 per cent colloidal silver iodide, 2 per cent Berlin Blue, and Neoprene Latex solution. The barium suspensions and the colloidal silver, being radio-opaque, could be subjected to radiological analysis and, when necessary, microradiography; other injection media were studied by different techniques. Neoprene I atex casts of the vascular tree, obtained by digestion of the bone and marrow with acid after intra-arterial injection of Neoprene, can be dissected under water; Spalteholz's technique, by which the bone and marrow are rendered transparent, enables the vessels previously filled by one or more injections to be followed for long distances throughout their course by a binocular dissecting microscope. We have employed a number of different methods to reveal the vessels in order to minimise the errors of interpretation that can arise from the use of any one technique.

Radiographs were made in the antero-posterior and the medio-lateral positions of each specimen that had been injected with radio-opaque material. The specimen was then sawn up into slices approximately a quarter of an inch thick, the plane of section varying from specimen to specimen. These slices were radiographed at right angles to the plane of their section and were then decalcified; when this process was complete all the radiographic views described above were repeated, it being possible to reconstruct the specimen by fitting together the several slices. On many occasions stereoscopic radiographs were taken for any or all of the above projections. The microradiographic techniques used were those described by Barclay (1951).

The study of the smaller vessels has been mainly effected by microscopy of histological preparations obtained from injected material. Tissue embedded in 20 per cent low viscosity nitrocellulose was cut at thicknesses of either $15 \mu$ or approximately $400 \mu$. Whereas the former were stained with Hansen's haematoxylin and eosin, the thicker sections were examined unstained by low power microscopy.*

\section{RESULTS}

We have found that the vascular patterns established during the phase of growth are not replaced at maturity but largely persist throughout life, and thus one can speak of epiphysial and metaphysial circulations even in advanced years; we shall show below that when the two territories become one by the disappearance of their cartilaginous frontier their circulations still retain some autonomy. The epiphysis and the metaphysis usually receive blood from separate sources and we shall call the vessels epiphysial and metaphysial in accordance with their destinations. By reference to their sites of entry into the bone (Fig. 3) the epiphysial arteries are named lateral and medial, and the main metaphysial arteries superior and inferior. The lateral epiphysial and both groups of metaphysial arteries usually arise from the medial femoral circumflex artery; the medial epiphysial artery is a continuation of the artery within the ligamentum teres which comes from the acetabular branch of the obturator artery.

A detailed assessment was made of the relative contribution that these sets of vessels made within each territory, and for this analysis fifteen injections were selected whose quality was such as to allow the finer branches of each artery to be followed to their limits. It was found that the lateral epiphysial arteries predominate in the epiphysis and the inferior metaphysial arteries in the metaphysis. The lateral epiphysial arteries supplied at least four-fifths of the epiphysis in seven cases, in a further seven they supplied two-thirds of the zone and in one case slightly more than half. The inferior metaphysial arteries were found

* If a block is sectioned serially, cutting alternately at $15 \prime \prime$ and $400 "$, it is possible not only to follow any vessel throughout the block by studying the thick unstained sections, but accurate superimposition of a stained thin section over its preceding or following thick section will allow identification of any particular vessel. 
to supply about two-thirds of the metaphysial tissue that is within the femoral head. These proportions represent only the more usual arrangement and must be subject to considerable variation; for example, the contribution coming from the artery of the ligamentum teres may be negligible or absent in some cases.

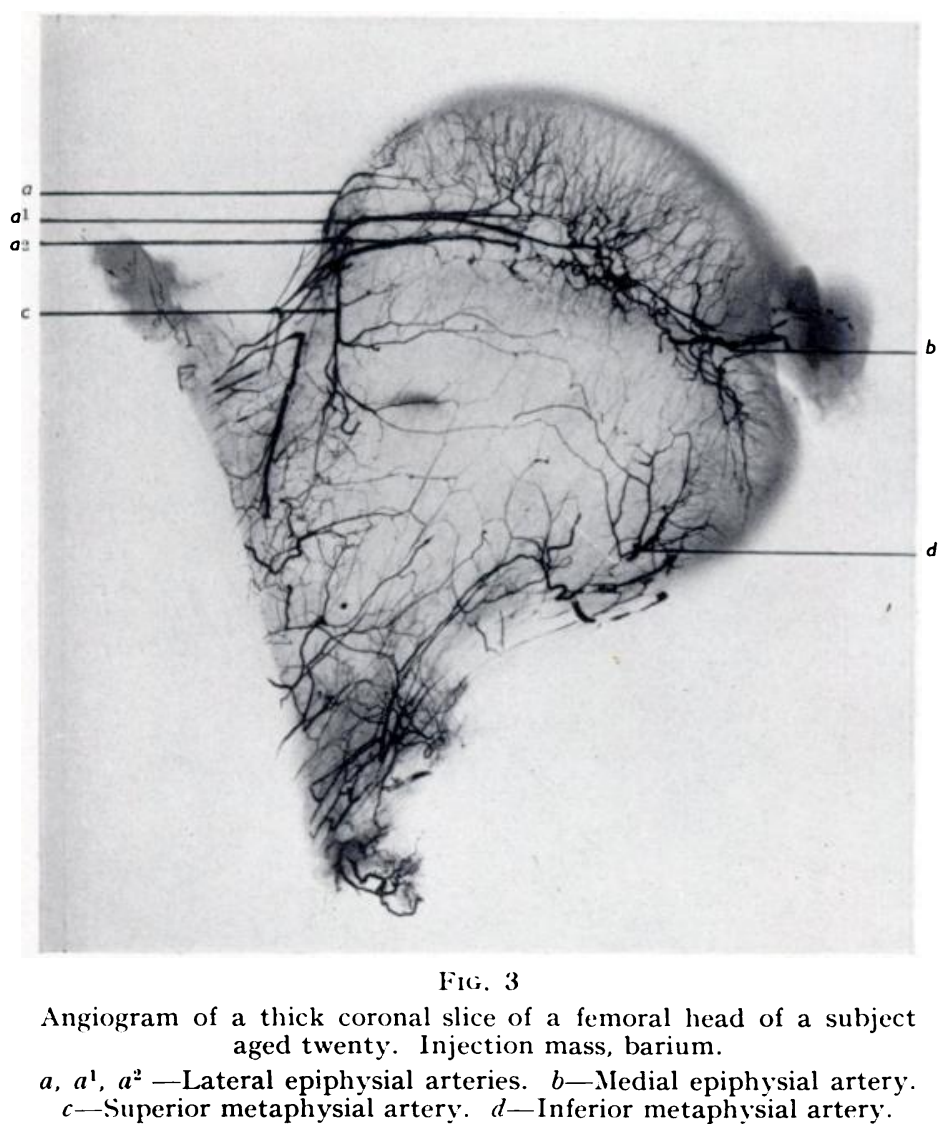

The epiphysial arterial pattern. The lateral epiphysial arteries (Figs 3, 6, 7, 12 and 23) enter the head superiorly and postero-superiorly, usually two to six in number and often spiral in form for a short distance after their entry (Fig. 4); in this position they always lie within a thick fibrous sheath (Fig. 5). In their course they follow closely the line of the old epiphysial plate, but lie some distance above it superficial to the epiphysial scar. They run downwards and medially, and, as can be seen in lateral radiographs, somewhat anteriorly as well, in a gentle curve directed towards a point on the articular surface between the fovea capitis and the inferior articular margin. The constituent arteries of the group vary in size: one is usually larger than the others and there is frequently one vessel whose branches are distributed exclusively to the supero-lateral segment of the epiphysis. The medial epiphysial artery (Figs. 3 and 23) and its main branches run laterally on the same level as the fovea capitis through which they have entered, until they meet and anastomose with the main lateral epiphysial vessels; the length of their course is proportional to their size. This anastomosis was frequently demonstrated by the outflow of the injection medium from the artery of the ligamentum teres on injection of the medial femoral circumflex artery.

The predominant direction of distribution of the branches from these main epiphysial arteries is into the epiphysis and towards the joint surface; in comparison the outflow to the metaphysis is small. The epiphysial vessels are arranged in a characteristic series of arterial

vol. 35 B, No. 3, AUgust 1953 


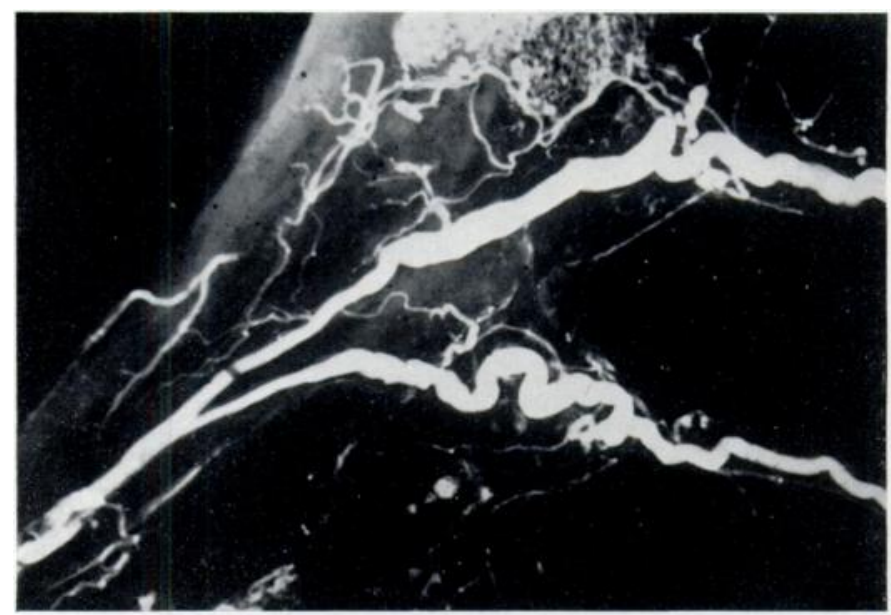

Fig. 4

Radiomicrograph showing a lateral epiphysial artery bifurcating immediately before entering the femoral head. Its branches describe a spiral in the first part of their intracapital course. Injection mass, barium $(\times 16)$.

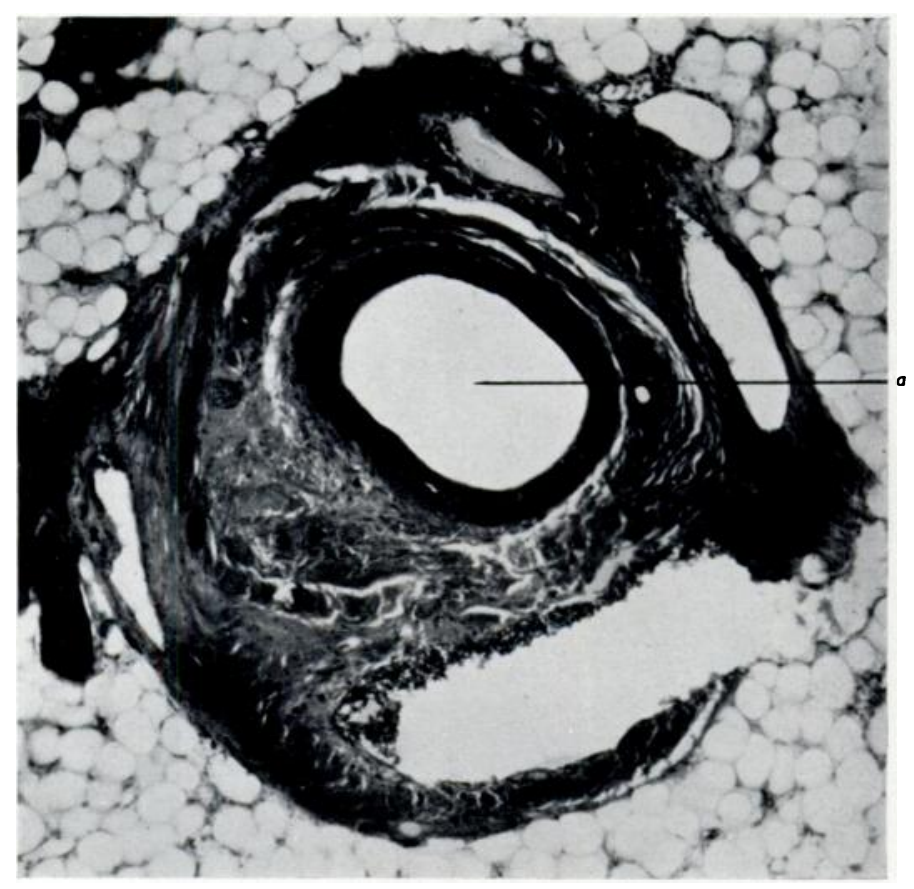

FIG. 5

Photomicrograph of a lateral epiphysial artery $(a)$ cut in the sagittal plane. The vessel was approximately at the position shown in Figure 4 and lies in the centre of a fibrous sheath which also contains four veins $(\cdot 52)$. 
arcades constituted in the following manner. The branches leaving the parent stem or its main divisions do so at an angle of approximately 90 degrees and follow a course directed perpendicularly to the joint surface; this radial arrangement obtains irrespective of whether the vessels are studied in coronal (Fig. 6), sagittal (Fig. 7) or horizontal sections. Neighbouring vessels running roughly parallel in this fashion form the sides of arches which are completed by a communicating branch usually of the same calibre as that of the two vessels it is uniting (Figs. 8 to 10). The summits of the arches, like their supporting pillars, are directed towards the surface and from these arches further branches are given off which themselves are subject to the same arrangement. Two or three tiers of such arches are found in the epiphysis lying

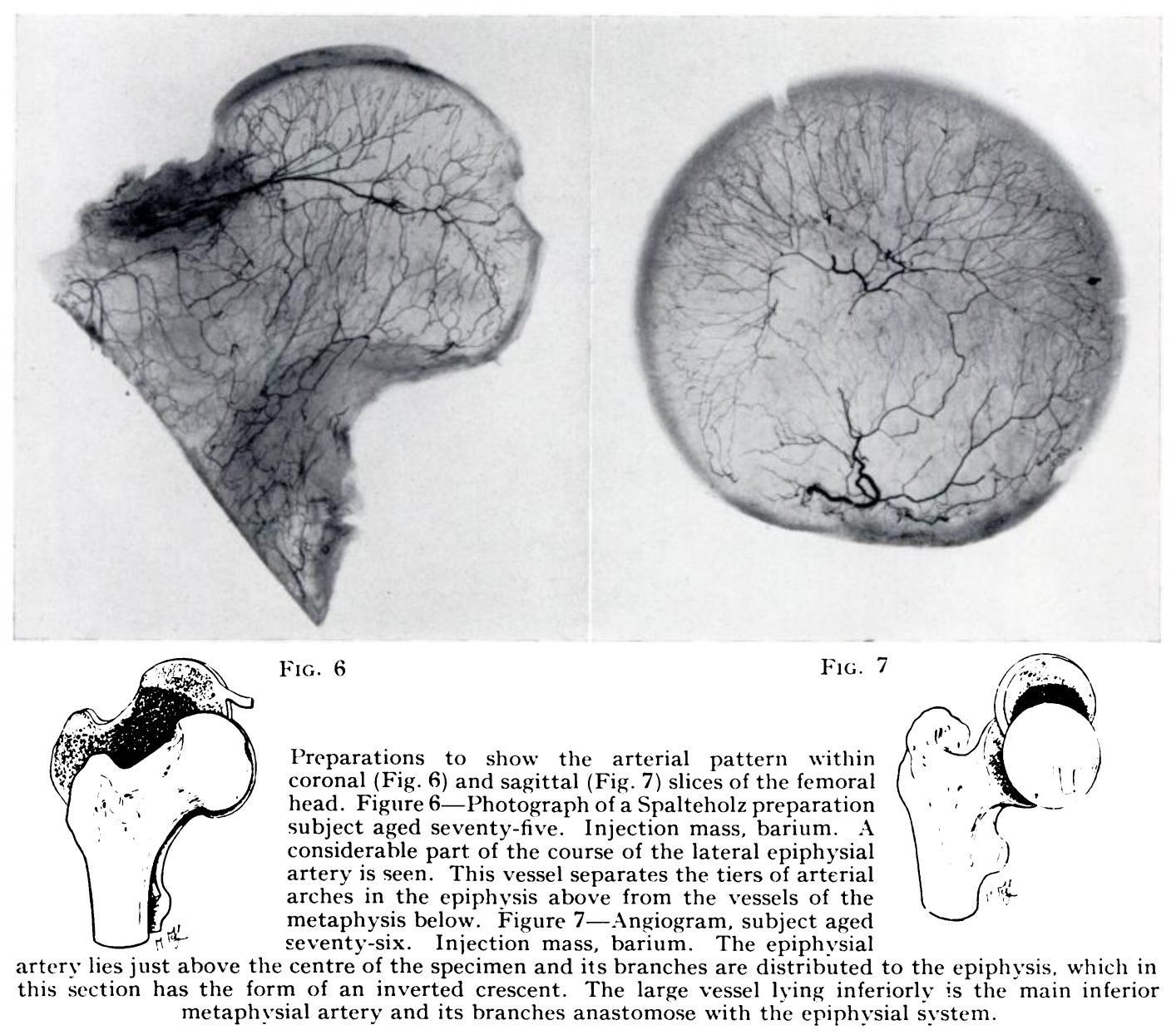

between the main vessels and the articular cartilage. Stereoscopic studies reveal that any one of the radially running branches can contribute to several arches lying in different planes; it is as though a series of fountains were arranged in such a fashion that the spray from any one fell into the rising columns of its neighbours on all sides. This characteristic pattern of the smaller intra-osseous arteries is a feature of the epiphysis and not merely of the branches of the lateral epiphysial artery; the branches arising from the medial epiphysial artery behave in exactly the same manner.

The metaphysial arterial pattern (Figs. 3, 6, 7, 12 and 23)-There are usually two, three or four superior metaphysial arteries arising from the vessels which will soon give origin to

vol. 35 B, No. 3 , August 1953 


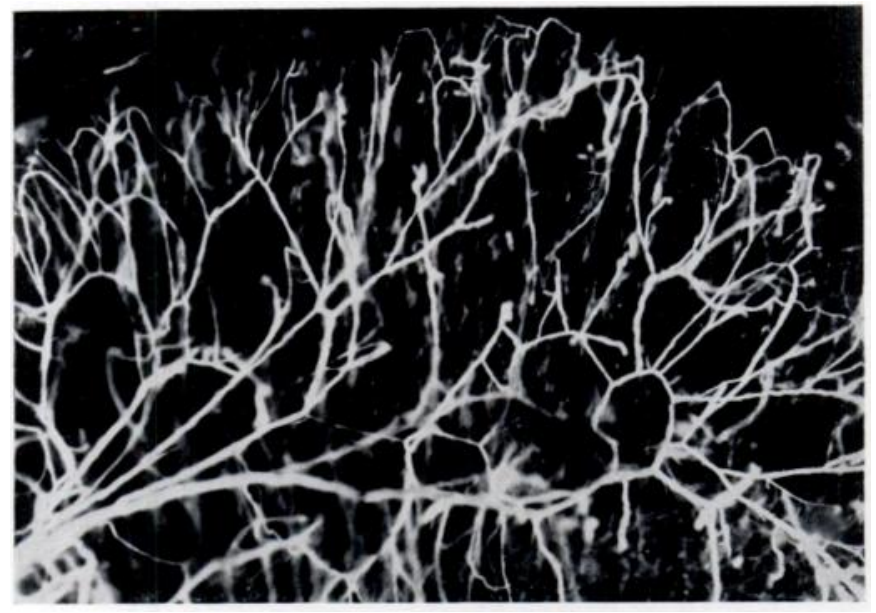

Fig. 8

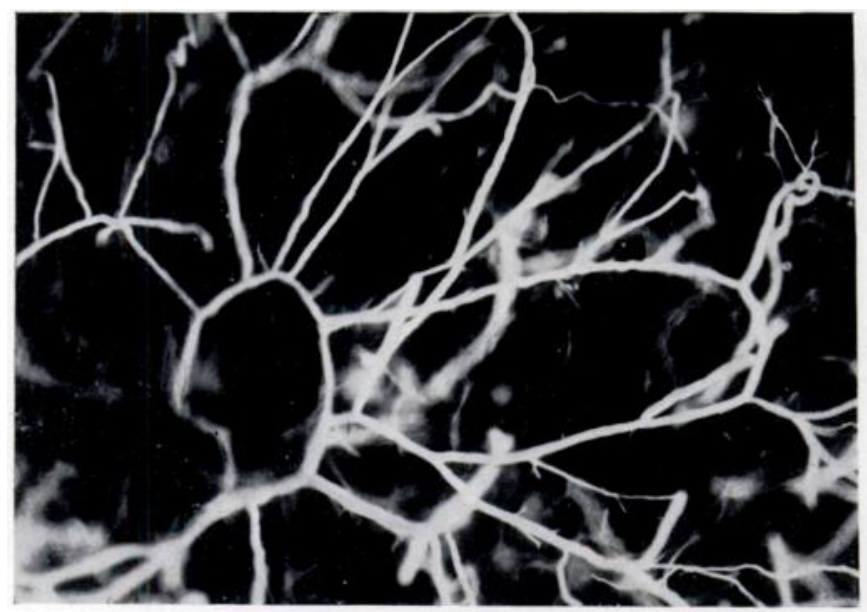

FIG. 9

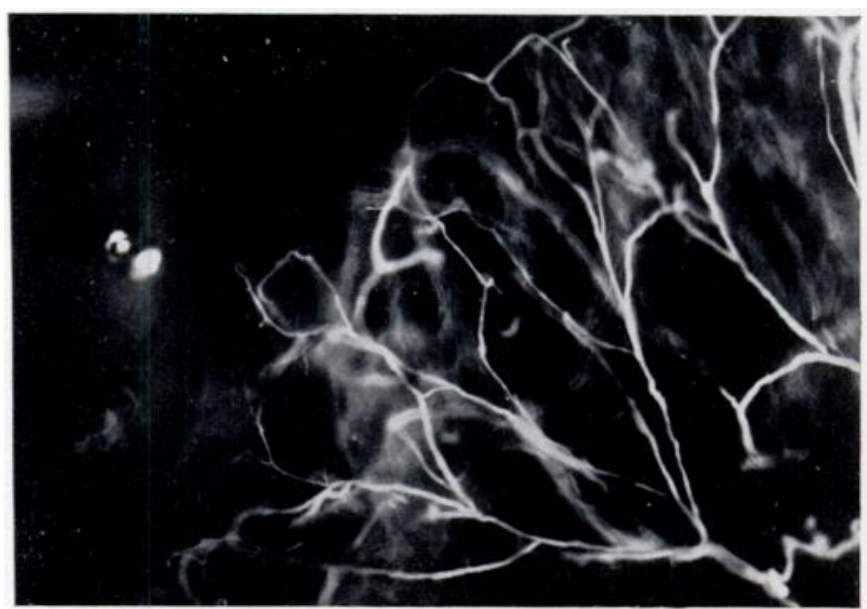

FIG. 10

Photomicrographs of the epiphysial arteries within the femoral head of a subject aged seventy-five. In Figure $\mathbf{8}$ are shown the tiers of arches running from the main lateral epiph ysial vessel below to the articular surface above $(\times \mathbf{2} \cdot \mathbf{6})$. Figures 9 and 10 show details of arch systems $(\times 6)$. Injection mass, barium. Spalteholz preparation. 
the lateral epiphysial group. These metaphysial vessels enter the superior aspect of the femoral neck some distance from the margin of the articular cartilage and have an absolutely straight course vertically downwards into the bone; when they have passed about a quarter of the way across the femoral neck they suddenly turn supero-medially in a smooth curve towards the site previously occupied by the epiphysial plate. The inferior metaphysial arteries enter the bone close to the inferior margin of the articular cartilage. There is frequently one vessel larger than any other of the group and it describes a short spiral before breaking up into branches which run up towards the epiphysis. The smaller arterial branches from these sets of metaphysial vessels are distributed throughout the metaphysis; the arching system of anastomoses seen in the epiphysis is absent here and the pattern is more one of branching vessels of decreasing calibre pursuing straight or angular courses towards the epiphysis.

The terms superior and inferior metaphysial arteries apply to groups of vessels which are in some respects less well defined than the lateral and medial epiphysial arteries. Before they enter the bone, the metaphysial arteries, by their frequent interconnecting anastomoses

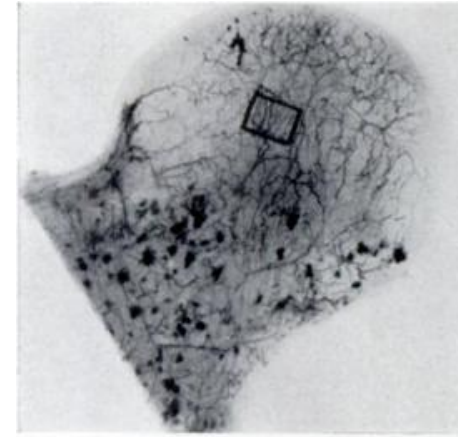

FIG, 11

The radiomicrograph on the right shows the spiral anastomotic vessels $(x 18)$ which, as can be seen in the smaller angiogram above, connect the epiphysial and the metaphysial circulations. Injection mass, barium.

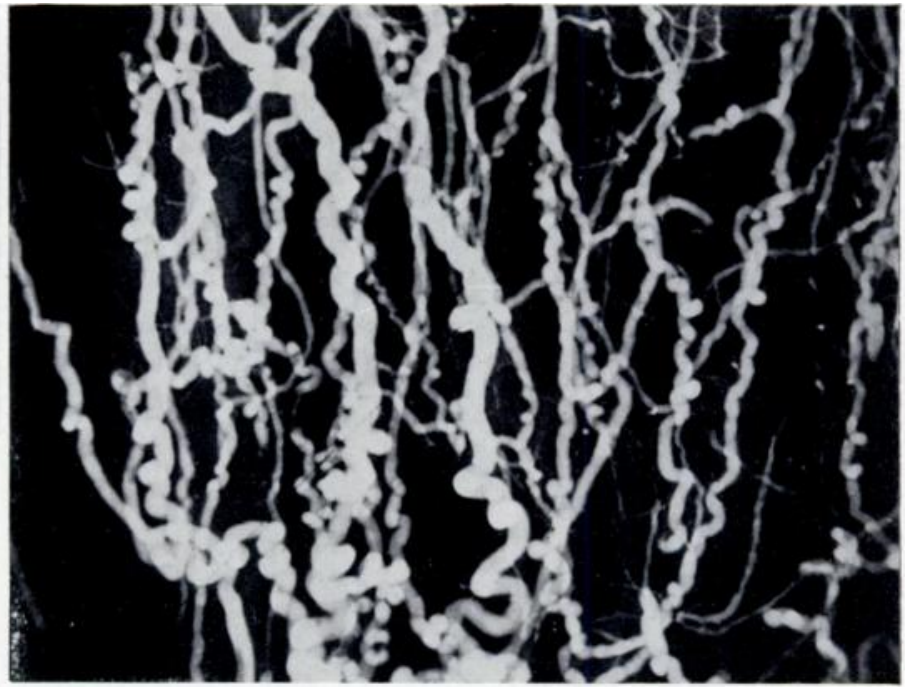

in the sub-synovial tissues, conform to the pattern so clearly described by Hunter (1743) and named by him the circulus articuli vasculosus. On the neck of the femur the circle tends to be deficient anteriorly, and "the vascular border of the joint " is most evident superiorly and inferiorly; it is here that the main arteries running to the metaphysis are found. Quite frequently the circle has some representation posteriorly in virtue of small arteries on the back of the femoral neck running in part into the metaphysis but we have not described these as a separate metaphysial group, rather preferring to emphasise the major sources.

Anastomoses - There is a free anastomosis inside both the epiphysis and the metaphysis between the ressels which supply each territory; in addition there is anastomosis between the vessels of the two territories at the site previously occupied by the growth plate. A series of connecting branches leave the main epiphysial arteries at right angles and run downwards into the metaphysis; in calibre they are usually smaller than the vessels of the epiphysial arches and in form they are frequently spiral (Fig. 11). Just as the metaphysis is a somewhat arbitrary subdivision of the diaphysis so the free anastomosis there of the metaphysial arteries and those within the neck of the femur prevents any attempt to define the lateral limits of the metaphysial circulation. It may be noted here that we have not seen any evidence of the nutrient artery of the femur extending its area of supply up to the metaphysial region as has been so frequently stated.

vol. 35 B, No. 3, At'Gi'st 1953 
Changes in the vascular tree with age-In this study we have examined specimens from persons who ranged in age from twenty to one hundred years and we have been impressed with the complete absence of any decrease in patency of the vascular tree with advancing years (Fig. 12). The failure to visualise a particular vessel or vessels by any of the techniques we have used gives no proof of their absence. In our experience a complete filling of even the arterial tree has never been achieved; tissue which had yielded our best angiograms, on subsequent histological section showed areas in which the vessels, though present, had not been filled. Whether this failure is due to the crudity of our present methods or whether it implies an intermittency of the circulation such as some authors describe in other organs (Richards and Schmidt 1924, Krogh 1929) cannot be decided; it has certainly been observed that the vessels of resting zones in other tissues have been extremely difficult to fill by injection.

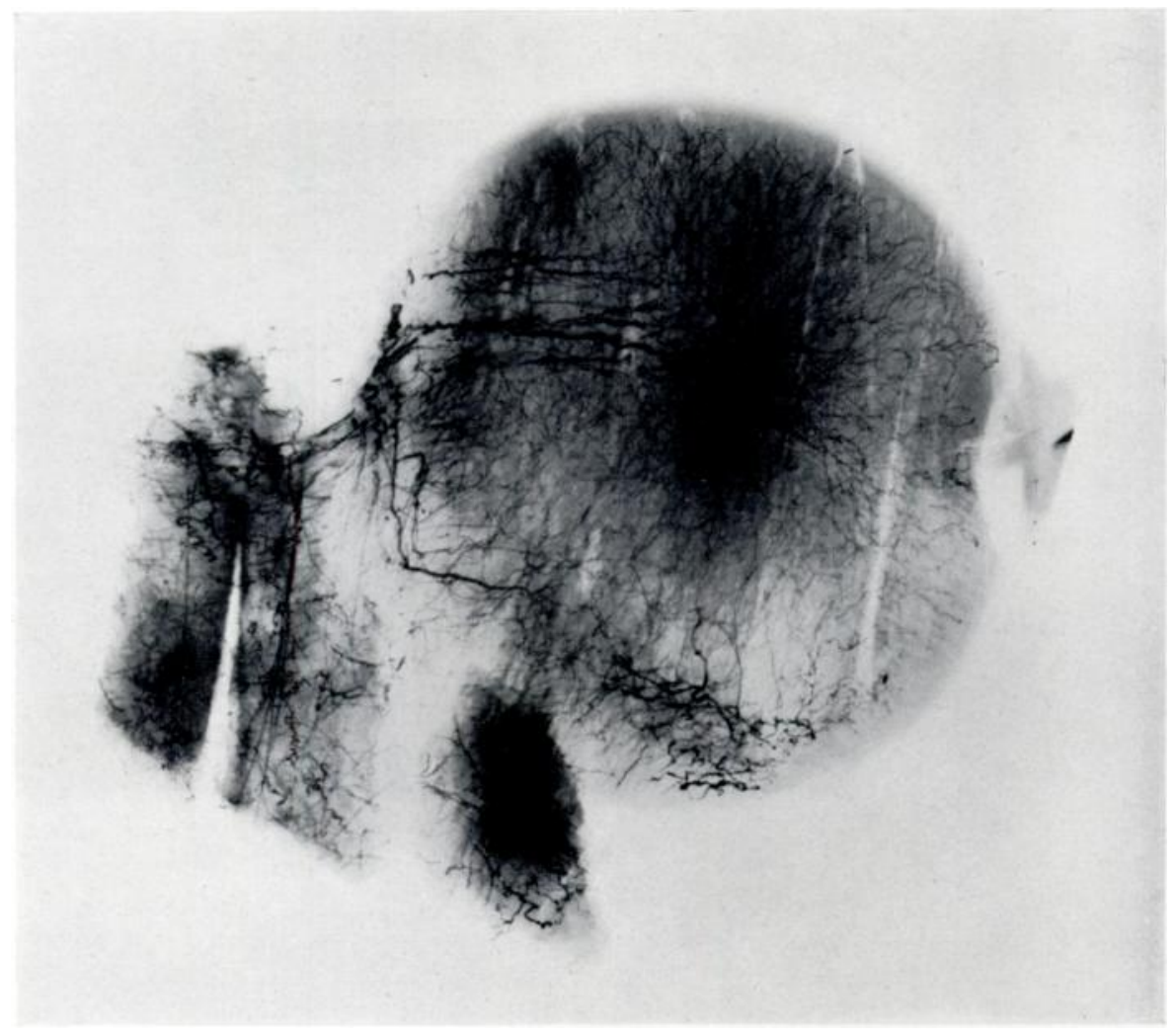

FIG. 12

Angiogram of a complete femoral head, subject aged seventy-six. Injection mass, barium.

The arterioles and smaller vessels of the marrow-Before we describe the smaller vessels that lead from the arterial systems already detailed, it is necessary to mention the distribution of the marrow within the upper end of the femur. This is because the arrangement of the small vessels, unlike that of the arteries, is independent of their situation in the epiphysis or metaphysis but is instead specific for the two types of marrow, yellow and red. During the years of growth the red, haemopoietic marrow is macroscopically visible both in the epiphysis and the metaphysis of the upper end of the femur; in normal adult life we have seen it mainly restricted to two areas, the metaphysis and a zone of epiphysis underlying the articular cartilage and the fovea capitis (Figs. 13 to 15). Most of the epiphysis is occupied by inactive yellow fat. Frequently we have seen a sharp line of demarcation between the two differently coloured marrows of epiphysis and metaphysis and the junction is a reminder 
of the situation the growth plate previously occupied.* In those specimens in which the metaphysis is only partly occupied by red marrow this striking partition is, of course, not seen. These findings are curiously at variance with many statements in the literature which localise the red marrow to the epiphysis or to the proximal portions of the adult femur.

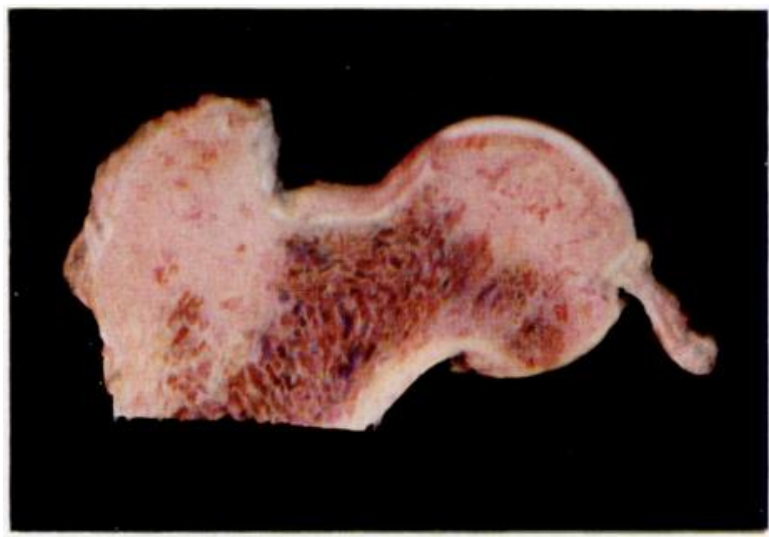

FIG. 13

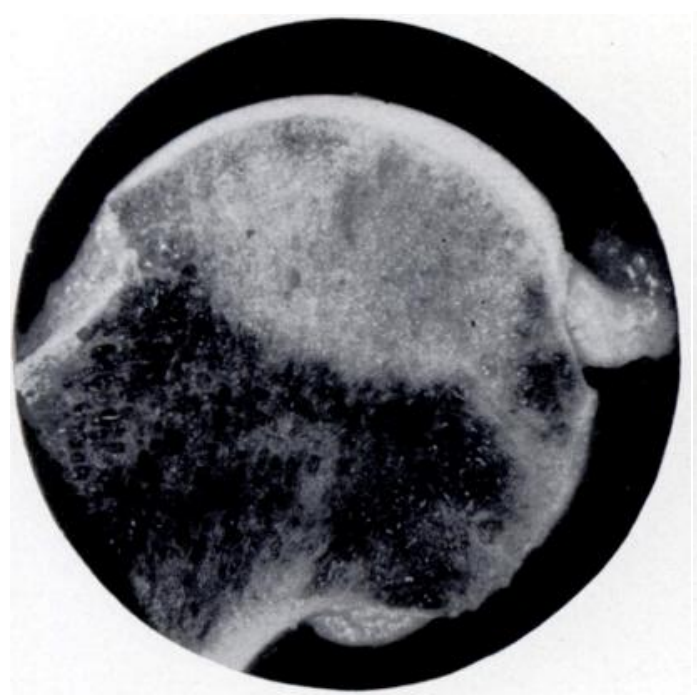

Fig. 14

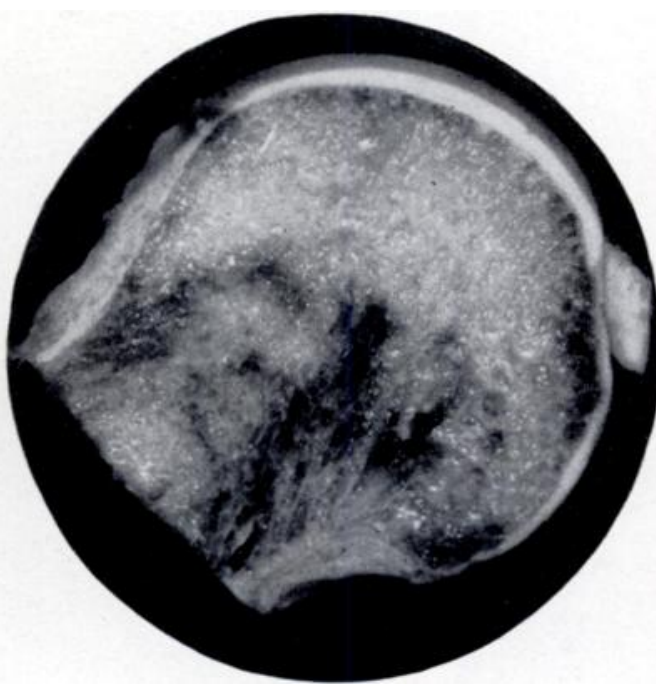

FIG. 15

Coronal sections of femoral heads. The epiphysis is largely occupied by yellow marrow and the metaphysis by red. Figure 13-Femoral head of a subject aged seventy-six. Figure 14 - Femoral head of a subject aged fifty-six. Figure 15-Femoral head of a subject aged fifty-three.

Microscopically there is no clear-cut separation of the marrow into yellow and red; the two forms merge gradually into each other and there are an infinite number of marrow types ranging from the very cellular to the completely fatty. The red, cellular marrow consists of an argyrophil meshwork of reticular fibres attached to which are reticular cells. Within this mesh are found a great variety of blood corpuscles showing all degrees of development, occasional fat cells and the highly characteristic spacious thin-walled blood vessels, the

* We are aware that some of the specimens in which this observation was made may not come within the limits of strict normality in that the main or contributory cause of death may have provoked some increased haemopoiesis. Nevertheless the findings illustrate the individuality that the metaphysial marrow can show in its haemopoietic activity.

vol. $35 \mathrm{~B}$, xo. 3 , AUgust 1953

$$
\mathrm{H}_{(8)}
$$




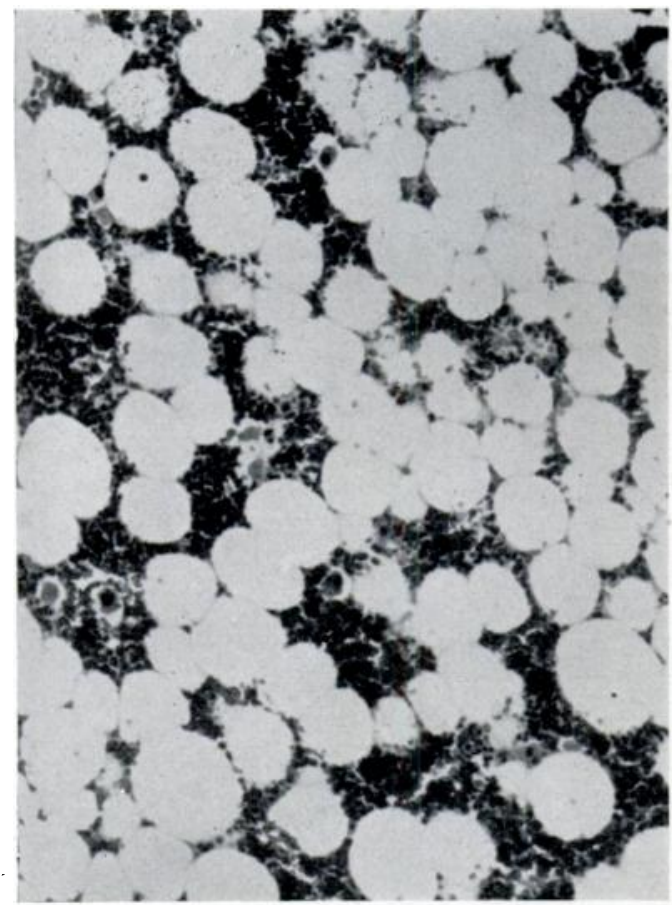

FIG. 16

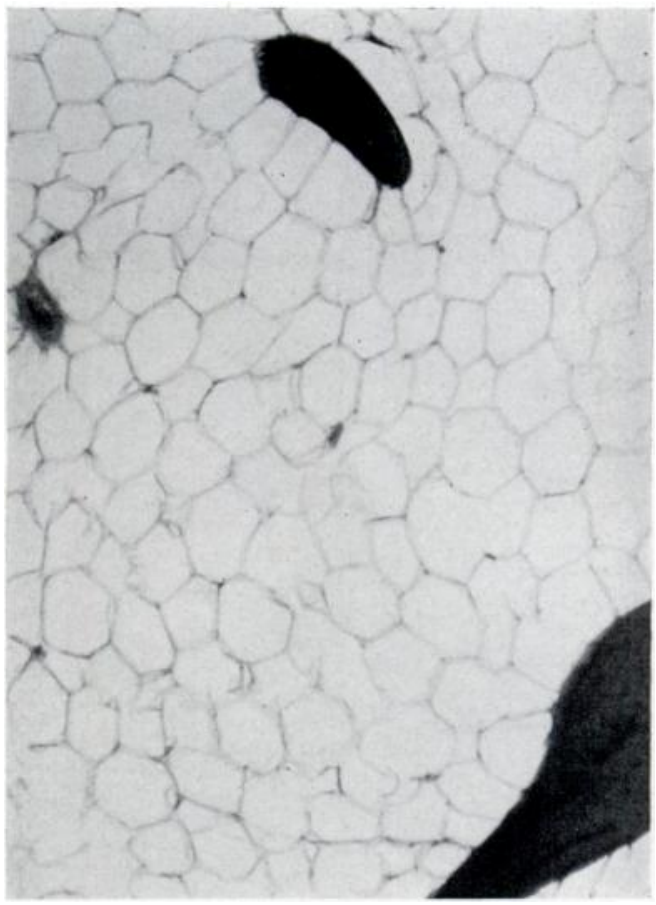

FIG. 17

Photomicrographs of sections of the bone marrow $10 \mu$ thick. Figure 16 - The red marrow $(\times 105)$ Figure 17-The yellow marrow $(<70)$. The difficulties of determining vascular arrangements in these types of preparation are obvious.

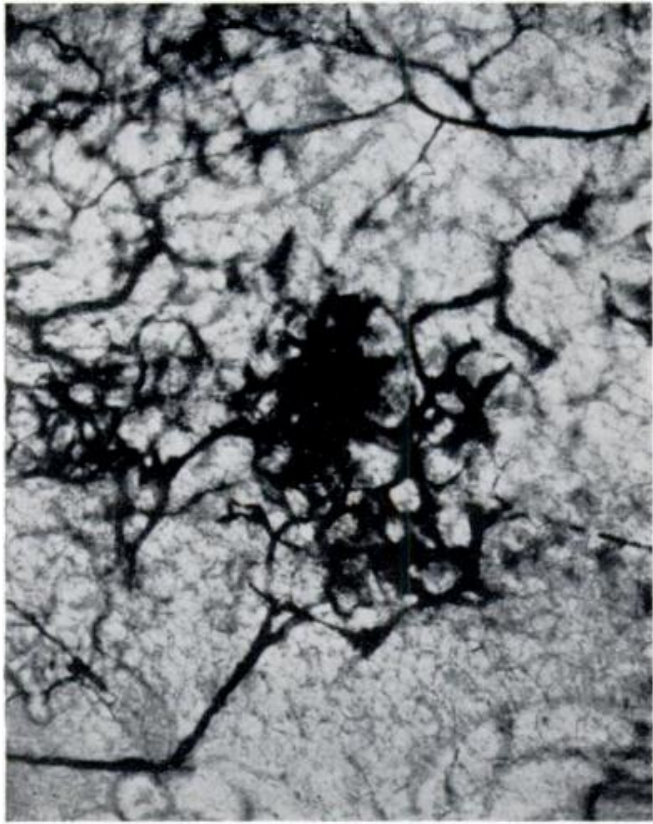

FIG. 18

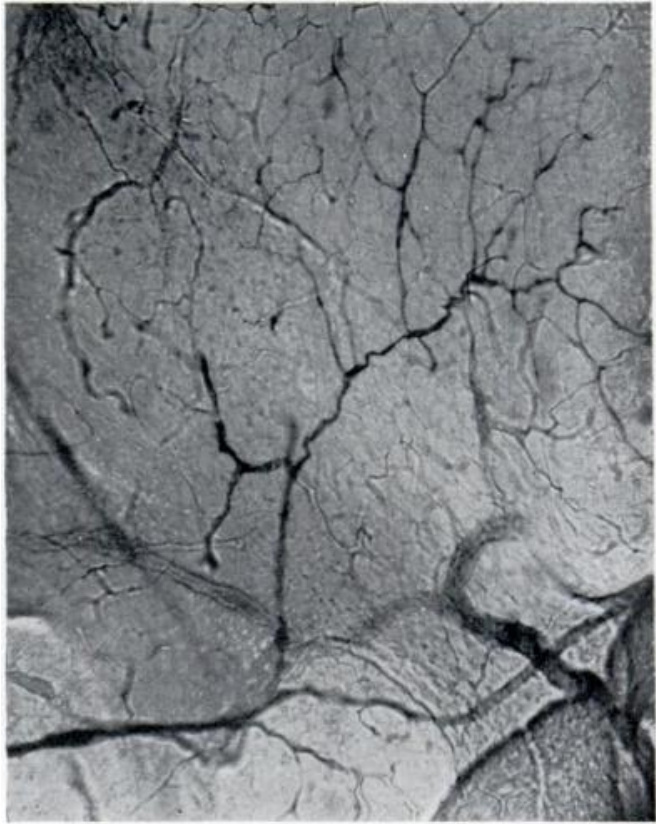

Fig. 19

Photomicrographs showing the vessels within the haemopoietic marrow (Fig. 18) and the fat marrow (Fig. 19). In both, an afferent vessel enters the field at the bottom left-hand corner. Injection mass, Berlin Blue; unstained sections $400 \mu$ thick. Figure 18 -The afferent vessel ends in the anastomosing meshwork of the sinusoidal bed $(\times 45)$. Figure 19-The afferent vessel distributes capillaries which run between the lobules of fat cells; sinusoids are absent. The large irregular vessel running to the bottom right-hand corner is a vein whose tributaries are coming from the capillary bed $(\times 75)$. 
venous sinusoids (Fig. 16). In the yellow marrow (Fig. 17) fat cells have replaced practically all these other types; scattered between the fat are small blood vessels of capillary size.

The arterioles of the marrow are singular in appearance in that throughout their course they undergo little or no decrease in calibre and their branches are approximately the same size as themselves; in their passage through the marrow they pursue a straight course, changing direction by sudden angulations. The blood conveyed by the arterioles eventually reaches one of the two available destinations, either the sinusoidal circulation of the red marrow (Fig. 18) or the capillaries of the fat marrow (Fig. 19). The fine-walled vessels of the haemopoietic areas, wherever they may be within the bone, take the form of the sinusoids (Figs. 20 to 22). These combine to form an irregular bulging and profusely anastomotic network which is found to correspond to the lobules of the red marrow; several precapillary vessels bring blood from various directions to each clump of sinusoids. Although the sinusoids are many times the size of ordinary capillaries their walls are as thin as the capillary wall. We have not found any evidence of an open circulation due to fenestrae in the sinusoidal wall, although it must be noted that the collections of injection material which we have accepted as extravasation due to rupture of the vessel wall have always occurred within the sinusoidal meshwork (Fig. 23).

The capillaries lying between the fat cells of the yellow marrow (Figs. 24 and 28) are similar to capillaries in other tissues. They arise from precapillary arterioles and drain into venules, and this type of circulation is also found scattered throughout the red marrow in those parts where fat cells are present in addition to the haemopoietic elements. In the capillary network the point of union of one capillary with another is frequently marked by a conical enlargement of the otherwise narrow lumen.

The many variations in the cytology of the marrow alluded to above are paralleled by the variations in the vascular picture; the capillaries and sinusoids are not only continuous but every grade of their admixture and partition is seen.

The relationship of the articular cartilage to the blood vessels of the bone-Normal articular cartilage is avascular, but in two situations it comes into contact with capillary vessels: on its deep attached surface and at its peripheral margin. The basal layers of the cartilage which are apposed to the underlying bone are calcified and the subchondral bone does not form an absolute barrier isolating this tissue from the circulation within the femoral head. Precapillary vessels arising in the marrow pass through canals in the subchondral bone (Figs. 25 to 27) and form single broad capillary loops at the deep surface of the calcified cartilage; post-capillary venules return from these loops through the canals to the marrow. This single capillary system regularly arranged against the deep surface of the cartilage is different from anything else seen within the marrow circulation and appears to be specific to the chondro-osseous junction. We have been unable to determine any specific arrangement of capillaries in the subsynovial tissues at the circumference of the normal articular cartilage. The veins-Our knowledge of the venous anatomy is as yet incomplete. The venous radicles coming from the capillaries (Fig. 28) and the sinusoids are broader and run a more irregular course than the equivalent arteries. In certain zones, such as the inferior metaphysial region, venules draining the sinusoids empty quickly into capacious thin-walled veins (Fig. 29); elsewhere veins of a smaller calibre commonly follow the course of an artery either alone when they may spiral around the latter (Fig. 30) or in association with another vein, one on each side (Fig. 31). In cross-section the larger veins which are soon to leave the head present a characteristic elliptical appearance as they lie adjacent to the artery in the fibrous sheath previously referred to (Fig. 5).

In our material certain observations made after injecting consecutively two materials differing both in colour and particle size have led us to suspect the existence of arterio-venous anastomoses within the bone. We have not so far been able to demonstrate these to our complete satisfaction.

vol. $35 \mathrm{~B}$, No. 3 , AUGUSt 1953 


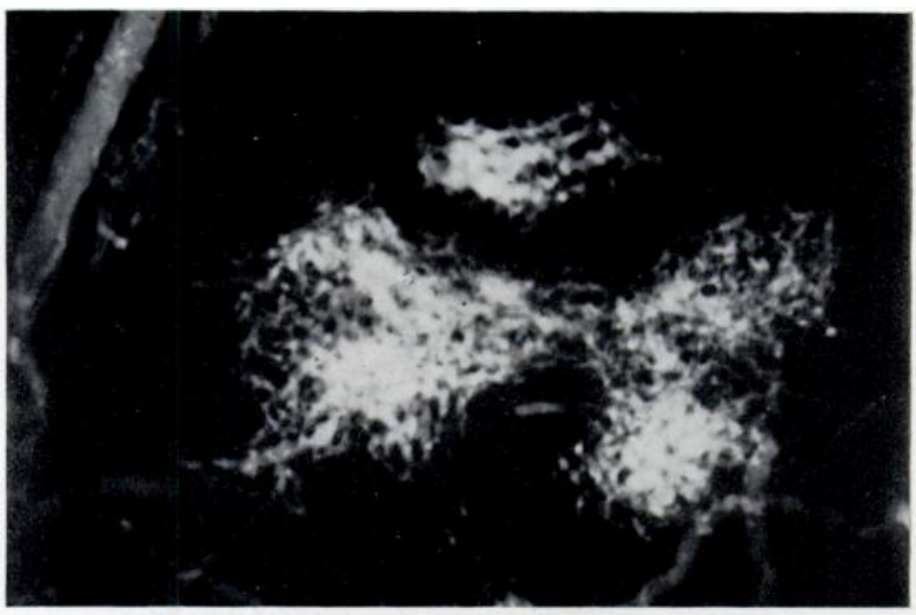

FIG. 20

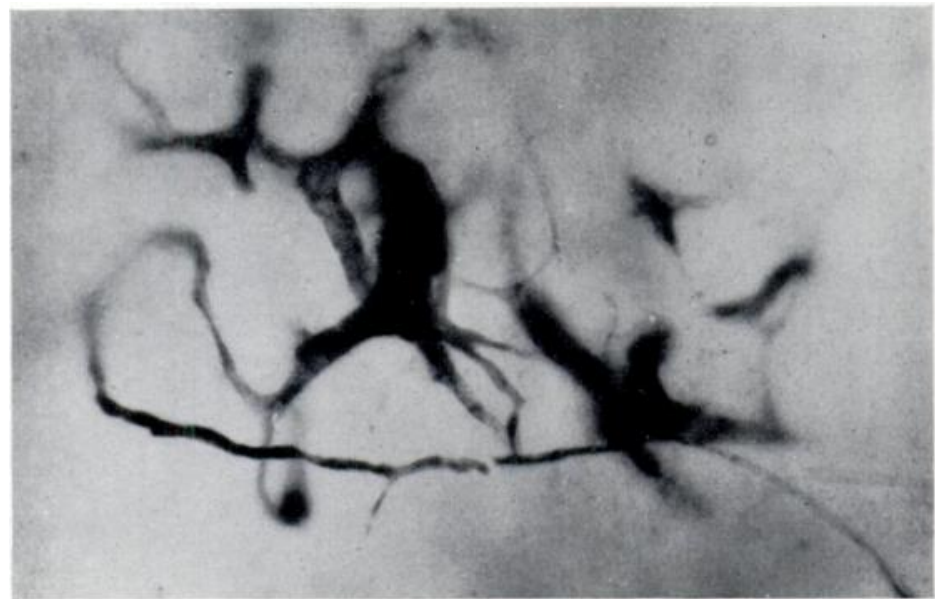

Fig. 21

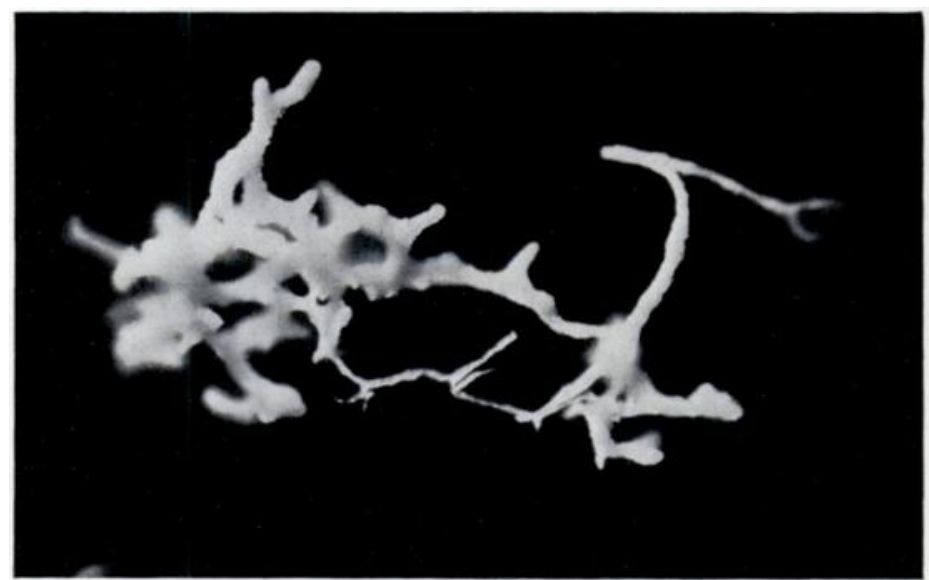

FIG. 22

The sinusoids of the haemopoietic marrow. Figure 20-Radiomicrograph showing four groups of sinusoids. The vessel on the left of the field is an artery. Injection mass, barium $(\times 18)$. Figure $21-$ Photomicrograph showing an afferent vessel leading into a sinusoid. Injection mass, Berlin Blue. Unstained section $400 \mu$ thick $(\times 174)$. Figure 22Photomicrograph of a Neoprene cast of sinusoids $(\times 50)$. 


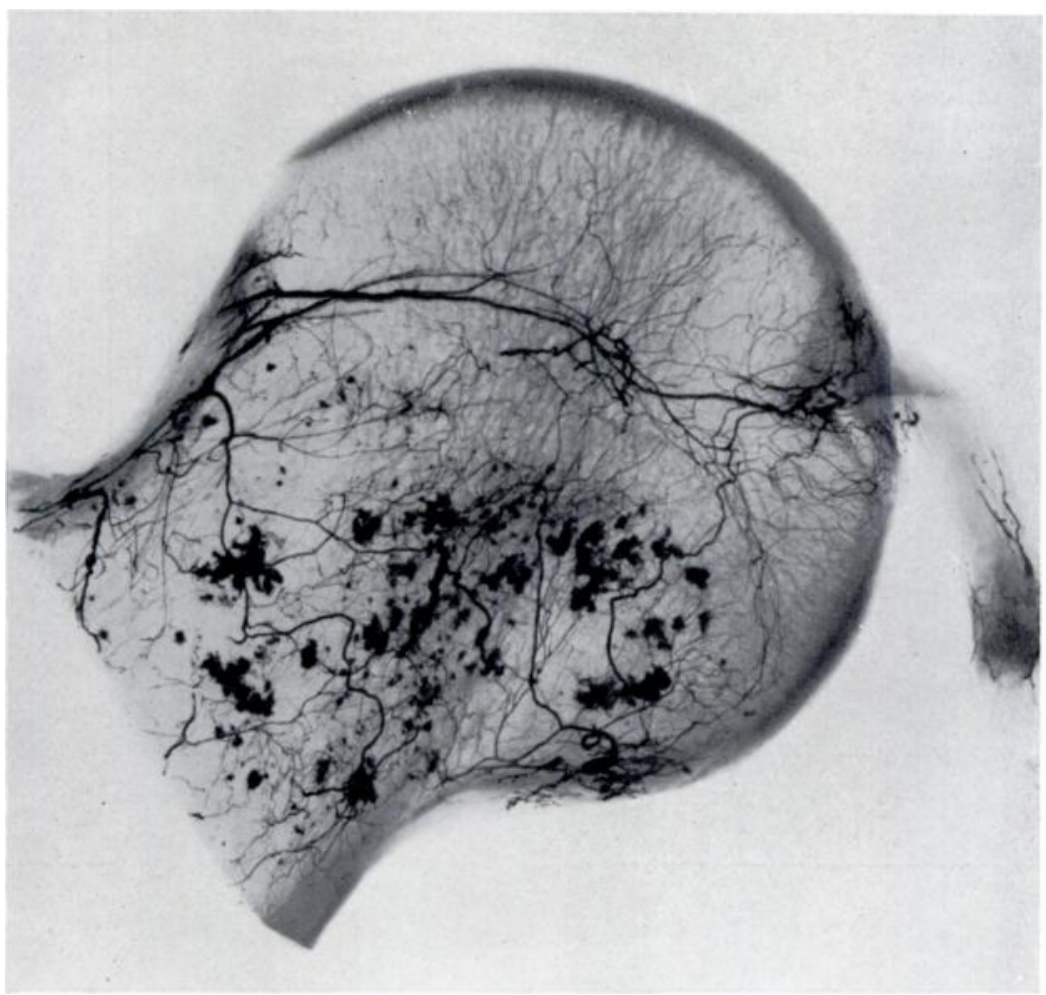

FIG. 23

Angiogram of a coronal slice of a femoral head, subject aged seventy. The irregular opacities within the metaphysis are mostly areas where sinusoids of the red marrow have in part been filled and extravasation has then occurred. Injection mass, barium.

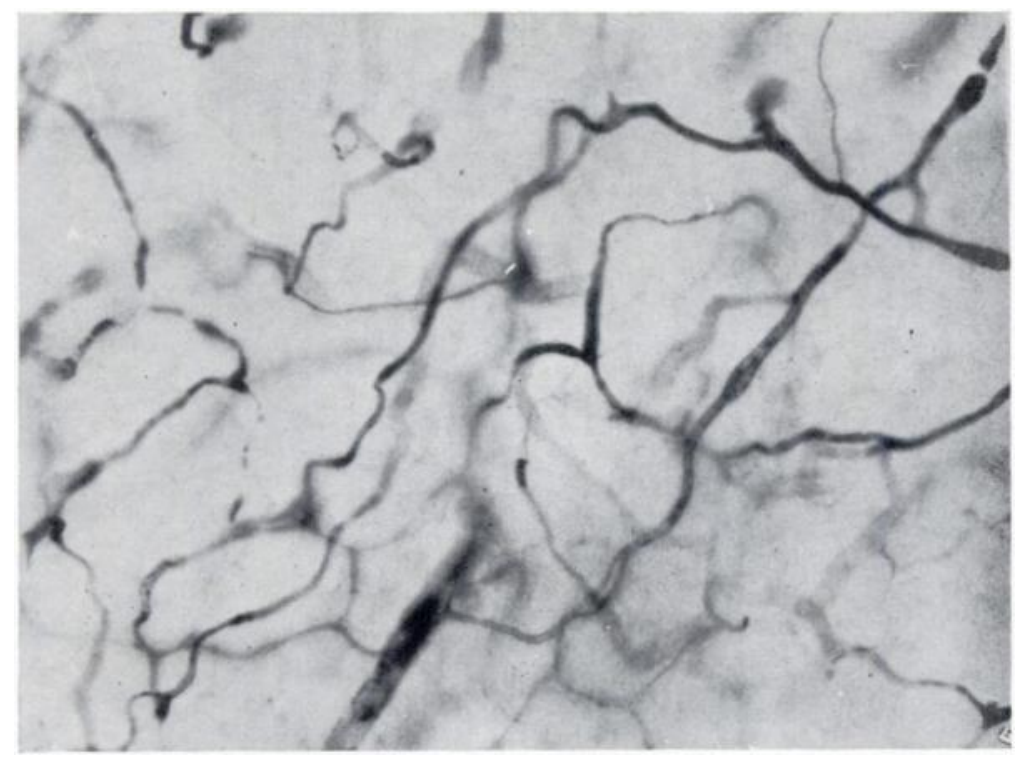

FIG. 24

Photomicrograph of capillaries within the fat marrow. Injection mass, Berlin Blue. Unstained section $400 \mu$ thick $(\times 174)$.

vol. 35 B, No. 3 , AUgust 1953

$\mathrm{HI}_{(8)}$ 


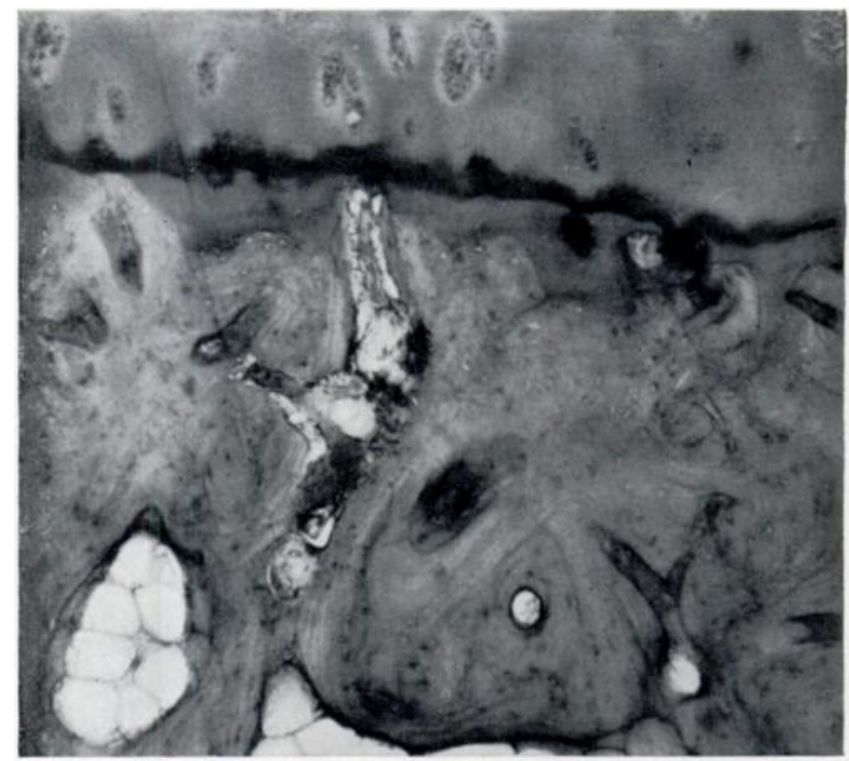

FIG. 25

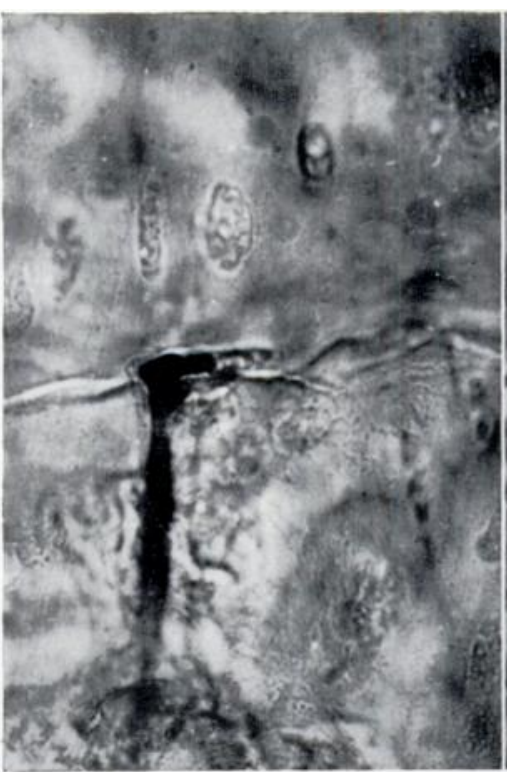

FIG. 26

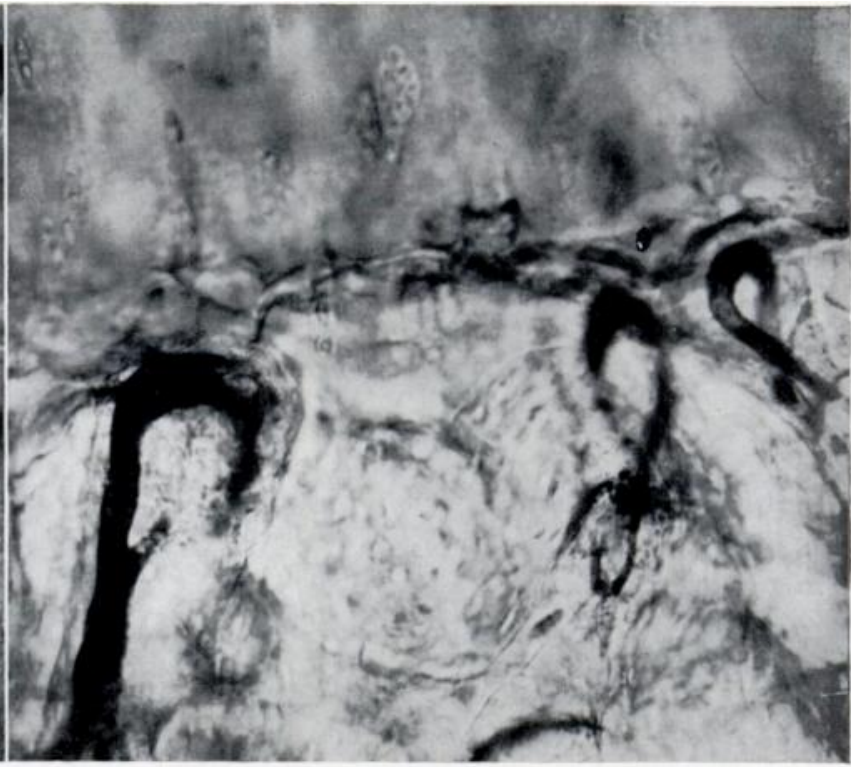

FIG. 27

Juxta-chondral blood vessels. Figure 25-Photomicrograph of the junction of articular cartilage and bone Canals in the subchondral bone lead up towards the calcified layer of the cartilage. The irregular horizontal wavy dark line marks the superficial border of the calcified cartilage (H.E. $\times 70)$. Figures 26 and 27-Two fields from a different specimen showing the junction between the articular cartilage above and the bone below. Four vessels pass up through the subchondral bone to the calcified cartilage, whose irregular upper border can be distinguished despite the unstained nature of the section which is 400 ! thick. Injection mass,

$$
\text { Berlin Blue }(\times 210) \text {. }
$$

\section{DISCUSSION}

We have emphasised that throughout maturity and even in old age we have been unable to detect any decrease in the richness of the arterial tree within the femoral head, and the only explanation we can offer for the many statements to the contrary that exist in the 
literature (Langer 1876, Walmsley 1915, Láng 1916, Kolodny 1925, Cheynel 1947 and Etienne and Granel 1949) is that these are based on technical errors and the wrong interpretation of negative findings. This integrity of the circulation in the older subjects is particularly noteworthy in relationship to the cartilage degeneration and other features of osteoarthritis which are encountered in joints increasingly commonly with advancing age (Heine 1926, Bennett et al 1942). In the course of another work we have confirmed the occurrence of these changes in the hip joint. The present report suggests that they are not preceded or accompanied by any general ischaemia within the femoral head. The marked changes in the vascular pattern which we have found to accompany the various stages and lesions of osteoarthritis will be detailed in a subsequent paper.

The lifelong persistence of the epiphysial arterial pattern, with the predominance therein

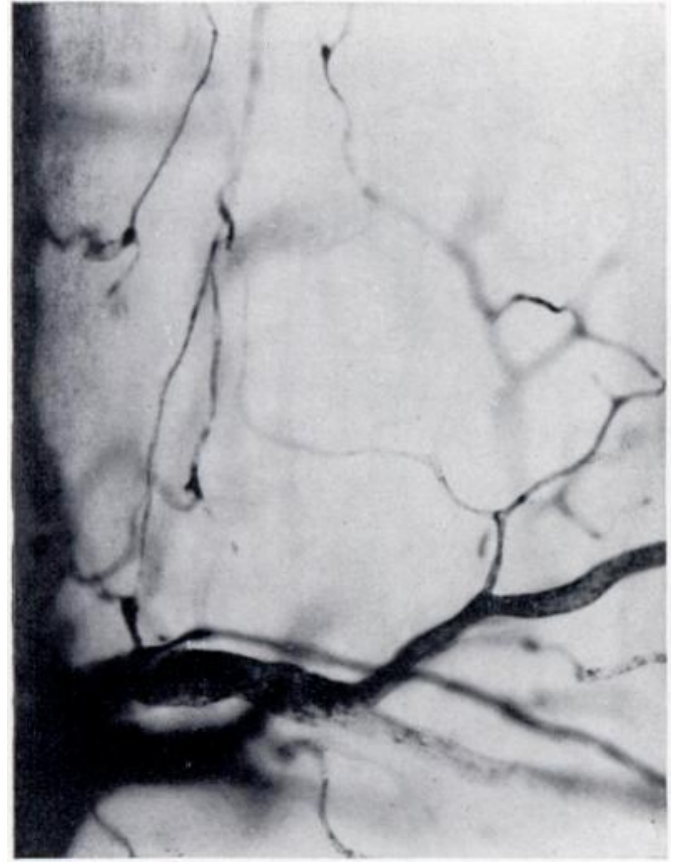

FIG. 28

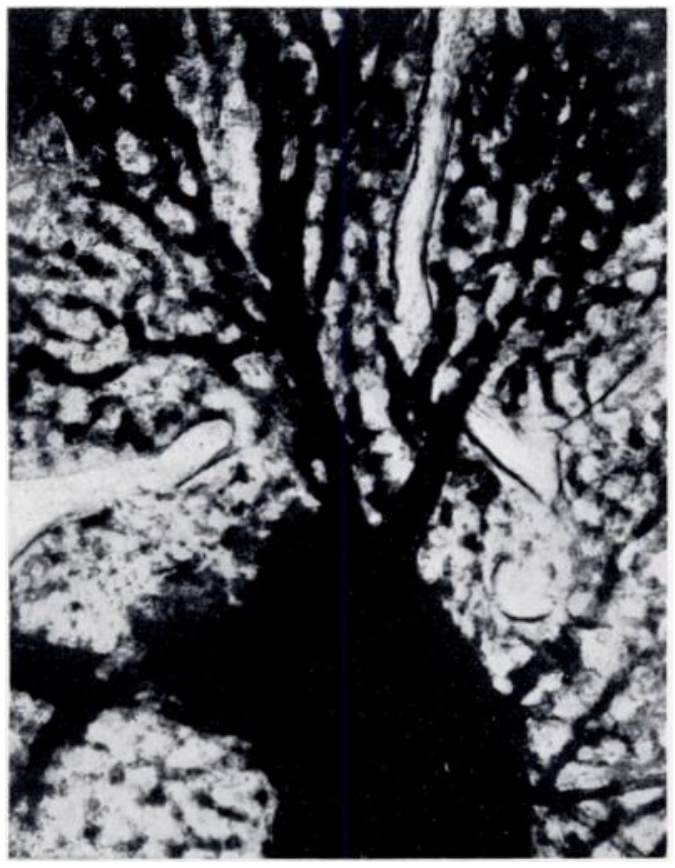

FIG. 29

Venous drainage of the marrow. Figure 28-Photomicrograph of the fat marrow showing capillaries draining into a venule in the lower portion of the field. This vessel proceeds into a vein. Injection mass, Berlin Blue. Unstained section $400 \mu$ thick $(\times 123)$. Figure 29 -Photomicrograph of the red marrow showing sinusoids in the top half of the field being drained by short venules into the large vein inferiorly. Injection mass. barium. Unstained section $400 \mu$ thick ( $\because 34)$.

of the lateral epiphysial arteries, may increase our understanding of one of the main factors responsible for the greater incidence of necrosis of the femoral head after unimpacted adduction fractures of the femoral neck when compared with abduction fractures. In the former variety the lateral epiphysial arteries are lying at the site of the greatest tearing of the tissues, whereas in abduction fractures these important vessels are not subjected to the same risk of injury.

The nutrition of cartilage has been the subject of an immense amount of research and is still an unsolved problem. The present study brings a contribution to this, in that it has revealed the form of a capillary system which appears to be directed towards the cartilage; the anatomical pathway for the conveyance of nutriments from the subchondral circulation to the cartilage can be said to exist. The canals in the subchondral plate and their termination 
close to the calcified zone of the cartilage can be seen in ordinary histological preparations of uninjected material, as has been recently emphasised by Holmdahl and Ingelmark (1950).

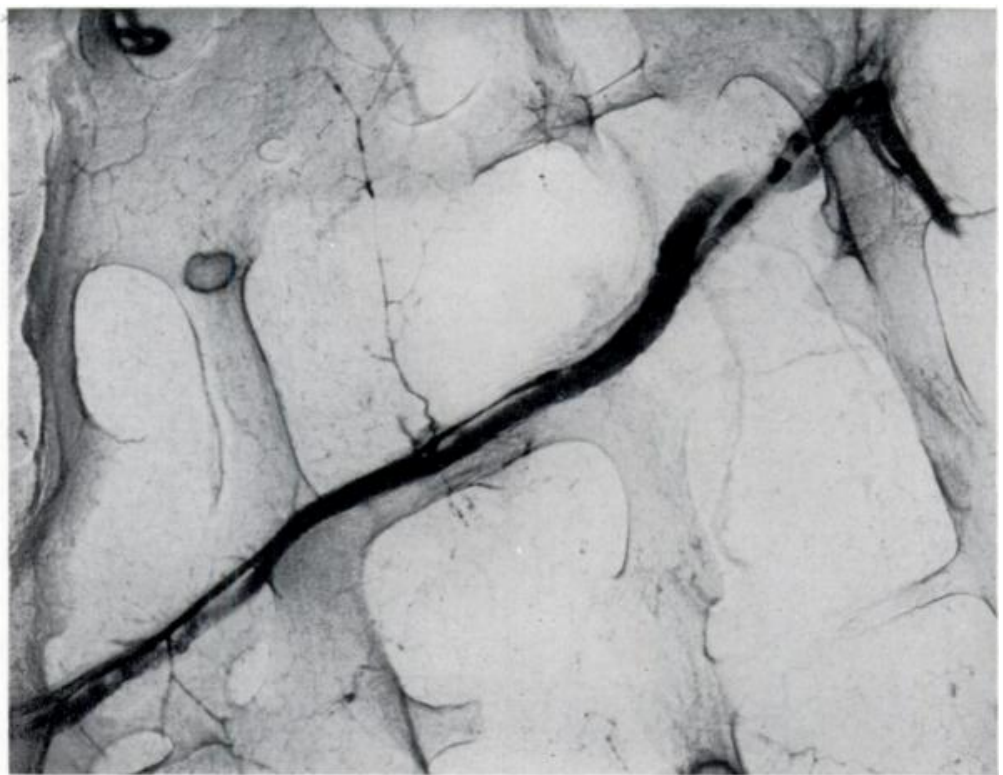

FIG. 30

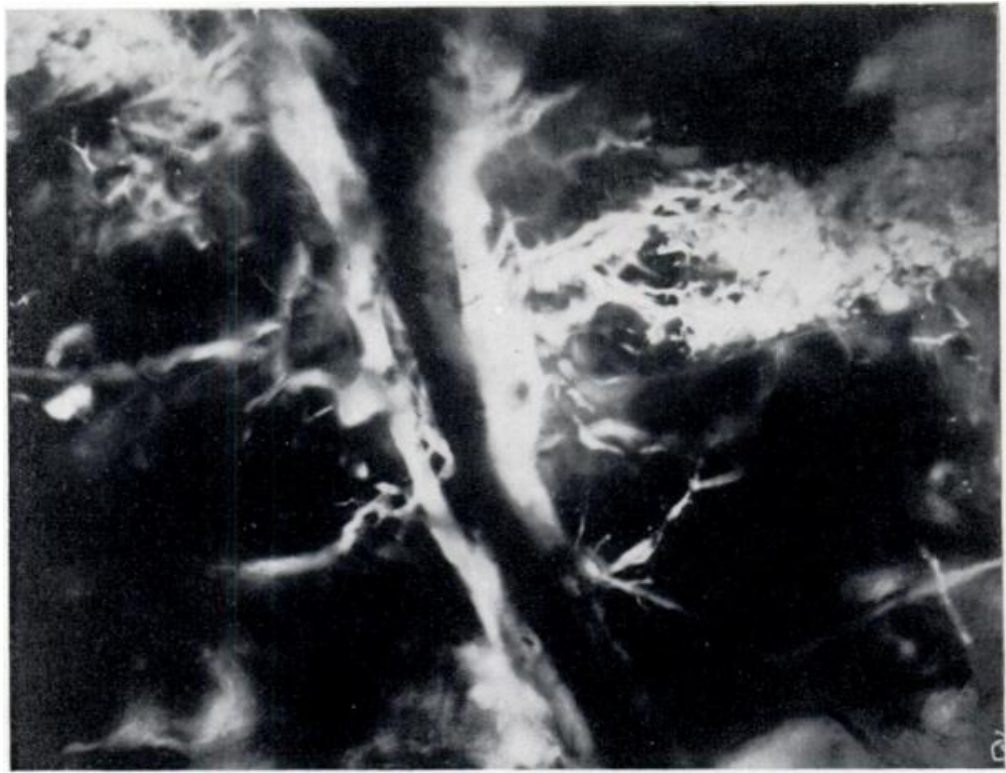

FIG. 31

The course of the veins. Figure 30-Photomicrograph. A single broad vein describes a gentle spiral around a slender artery. Injection mass, Berlin Blue. Unstained section $400 "$ thick $(\times 30)$. Figure $31-$ Photomicrograph showing two white venae comites, filled with barium, on either side of an artery filled with

Berlin Blue. Sinusoids are seen draining into the vena comes on the right of the artery. Spalteholz preparation $(\times 18)$.

Arteries of spiral form are seen frequently in our material. They are invariably present in the synovial membrane; other sites where their presence has impressed us by their frequency are the early intra-osseous course of the lateral epiphysial and the inferior 
metaphysial vessels, the site of the old growth plate and to a lesser extent the centre of the metaphysis. It is uncommon to find them in any profusion in the epiphysis. Their occurrence in the synovial membrane and at the point of entry of the main trunks into the head might suggest that the spiral shape serves to adapt these vessels to the demands of joint movement; but this explanation cannot be applied to those spiral vessels located deep in the head. The proximity of these latter to the sites of red marrow formation invites the suggestion that some correlation could exist between vessel form-assuming this is not an injection artefactand haemopoiesis. Reynolds (1948) working with the ovary, and Harrison and Weiner (1949) working with the testis, have considered the possible ways in which the spiral arteries associated with these organs could be related to the conditions necessary for the cellular proliferation that occurs there.

The description of the capillaries and sinusoids of the marrow which we have given is at variance with much that is to be found in the literature and we would suggest two reasons that might account for this. Firstly, previous investigators have worked mainly with animal tissues; and secondly, in the past, interpretations have been made from the study of thin microscopic preparations (less than 20 $\mu$ ); we have found these latter to be not only uninformative of vascular orientation but positively misleading. The finest anastomosing vessels within the fat marrow are true capillaries; the term sinusoid, coined by Minot (18991901) and first applied by Doan (1922) to the vessels of the haemopoietic marrow, seems to us an apt name in that it distinguishes these vessels from the capillaries within the fat. The sinusoids do not resemble capillaries morphologically nor does their form suggest the function inherent in the latter type of vessel.

Doan $(1922,1925)$, working with animal material, considered that the "venous sinusoids form normally the principal functioning vascular bed for the actively circulating blood in the marrow; i.e., they correspond largely to the capillaries of other organs." By the use of a special starvation technique he rendered the marrow of the pigeon hypoplastic, and then was able to demonstrate therein " a most extensive system of capillaries, hitherto unsuspected." He believed that these latter vessels were not connections between arteries and veins but ran from sinusoid to sinusoid, which structures they entered with a conical enlargement of their lumen; that this capillary bed was normally non-patent and functionally dormant as far as the active blood circulation was concerned; and that in the epiphysis the capillaries surrounded each fat cell. We have enumerated here the differences between the occult circulation described by Doan and the one that we have constantly found to be present and patent within the normal fat marrow; we have not seen in our material a collapsed intersinusoidal capillary bed such as Doan described. He believed that these capillaries were the site of erythropoiesis and that they might be thrown open to the circulation under conditions of increased activity of the marrow, as in anaemia (see below). Whatever their haemopoietic potentialities may be, we judge from their distribution and morphology that the capillary bed described above by us is responsible for the metabolic needs of the cells of the fat marrow.

We have described how the distinction between the vascular epiphysis and metaphysis can be made in the adult and that one of the hallmarks of the epiphysis is the arching arterial pattern. We have also seen that the common association between this pattern and the fat marrow of the epiphysis is not unchangeable. The constant association between vessel form and marrow type is found only in the finest ramifications of the arterial tree. Here the capillary net is the vascular counterpart of yellow marrow, the sinusoids of the red. This is well demonstrated in states of anaemia, in which the increased demand for red blood cells results in the transformation of the epiphysial marrow from yellow to red. The arterial arch pattern of the epiphysis is unchanged in such circumstances but the capillaries of the previously fatty marrow are replaced by sinusoids. Since there are, at this level of the circulation, only two types of vessel, the capillary and the sinusoid, we are unable to escape

vol. 35 B, No. 3 , AUGUST 1953 
the conclusion that such extension of the haemopoietic tissues is accompanied by the conversion of capillaries into sinusoids.

While it is dangerous to base speculations concerning function on morphological appearances, it seems likely to us that as the slender afferent vessels debouch into the capacious sinusoids the rate of blood flow therein must be severely slowed. The sluggish circulation which would thus obtain might in part be responsible for the arrest and localisation of metastatic tumour deposits and certain infections within the bones.

\section{SUMMARY}

1. The form and distribution of the blood vessels within the adult human femoral head are described.

2. It has been found possible to delimit the proximal femoral epiphysis in mature years by reference to arterial form alone.

3. Two morphologically different sets of vessels are described interposed between the arterioles and venules of the bone marrow. One, a true capillary bed, lies mainly within the fat marrow; the other, constituted by sinusoids, lies within the red marrow. The departure of these findings from current views is noted.

4. A capillary system is described in relationship to the calcified zone of the articular cartilage. 5. No evidence has been found in support of the common belief that the circulation within the femoral head decreases quantitatively with advancing age.

It is a pleasure to acknowledge the help we have received from many people in the course of this investigation. In particular, Dr G. M. Ardran, of the Nuffield Institute for Medical Research, Oxford, has not only provided all the radiographic facilities but has frequently given us his advice on the interpretation of results. Dr F. Schajowicz, of Buenos Aires, working in this centre for four months made available to us the full extent of his knowledge of the minute anatomy of the locomotor system. He introduced many valuable histological and microphotographic techniques and it was he who first pointed out to us the partition of the marrow described above. We are, however, most indebted to him for his never failing enthusiasm. We are grateful to Dr Robb Smith, Director of Pathology, Radcliffe Infirmary, Oxford, and Dr Cosin, Director of Cowley Road Hospital, Oxford, for the post-mortem facilities which they have extended to us. Lastly we would like to thank the staffs of the Photographic Department and the Pathological Laboratory of this centre, and in particular Mr Hill, our laboratory technician, for his invaluable help with every technical process involved in this investigation.

\section{REFERENCES}

Ardran, G. M. (1953): Modern Trends in Diagnostic Radiology. Ed. J. W. McLaren. Second series, Chapter V. (In Press.)

Barclay, A. E. (1951): Micro-Arteriography. Oxford: Blackwell Scientific Publications.

Bennett, G. A., Waine, H., and Bauer, W. (1942): Changes in the Knee Joint at Various Ages. New York: The Commonwealth Fund.

Cheynel, J. (1947): Recherches sur la Physio-pathologie de la Hanche: vascularisation de la tête et du col fémoral. Revue d'Orthopédie, 33, 7.

Cooper, Sir A. (1823): A Treatise on Dislocations and on Fractures of the Joints. Second edition. London: Longman, Hurst, Rees, Orme, and Browne.

Doan, C. A. (1922): The Circulation of the Bone-Marrow. Contributions to Embryology, Carnegie Institution of Washington, 14, 27.

Doan, C. A., Cunningham, R. S., and Sabin, F. R. (1925): Experimental Studies on the Origin and Maturation of Avian and Mammalian Red Blood-Cells. Contributions to Embryology, Carnegie Institution of Washington, 16, 163.

Drinker, C. K., Drinker, K. R., and Lund, C. C. (1922): The Circulation in the Mammalian Bone-Marrow. American Journal of Physiology, 62, 1.

Etienne and Granel (1949): A propos de la circulation du ligament rond. Revue d'Orthopedie, 35, 538. Harrison, R. G., and Weiner, J.S. (1949): Vascular Patterns of the Mammalian Testis and their Functional Significance. Journal of Experimental Biology, 26, 304.

Heine, J. (1926) : Uber die Arthritis. Virchow's Archiv für pathologische Anatomie und Physiologie, $260,521$. Holmdahl, D. E., and Ingelmark, B. E. (1950): The Contact between the Articular Cartilage and the Medullary Cavities of the Bone. Acta Orthopaedica Scandinavica, 20, 156. 
Howe, W. W., Jun., Lacey, T., and Schwartz, R. P. (1950): A Study of the Gross Anatomy of the Arteries Supplying the Proximal Portion of the Femur and the Acetabulum. Journal of Bone and Joint Surgery, 32-A, 856.

Hunter, W. (1743): Of the Structure and Diseases of Articulating Cartilages. Philosophical Transactions, 42, 514.

INGELmark, B. E. (1950): The Nutritive Supply and Nutritional Value of Synovial Fluid. Acta Orthopaedica Scandinavica, 20, 144.

Kolodny, A. (1925): The Architecture and the Blood Supply of the Head and Neck of the Femur. Journal of Bone and Joint Surgery, 7, 575.

Krogh, A. (1929): The Anatomy and Physiology of Capillaries. New Haven: Yale University Press.

LÁNG, A. (1916): Beiträge zur Lehre von den Schenkelhalsbrüchen auf Grund anatomischer und klinischer Studien. Deutsche Zeitschrift für Chirurgie, 135, 101.

LANGer, E. (1876) : Ủber das Gefässystem der Röhrenknochen. Denkschriften der Kaiserlichen Akademie der Wissenschaften, 36-37, 1.

Lexer, E., Kuliga, P., and TURK, W. (1904): Untersuchungen über Knochenarterien mittelst Röntgenaufnahmen injizierter Knochen und irhe Bedeutung für einzelne pathologische Vorgänge am Knochensysteme. Berlin: A. Hirschwald.

Logròscino, D. (1934): La Tuberculosi del collo del femore. La Chirurgia degli Organi di Movimento, 19, 295. Minot, C. S. (1899-1901): On a Hitherto Unrecognised Form of Blood Circulation without Capillaries in the Organs of Vertebrata. Proceedings of the Boston Society of Natural History, 29, 185.

Neumann, E. (1869): Ueber die Bedeutung des Knochenmarkes für die Blutbildung. Ein Beitrag zur Entwicklungsgeschichte der Blutkörperchen. Archiv der Heilkunde, 10, 68.

Nussbaum, A. (1924): Die arteriellen Gefässe der Epiphysen des Oberschenkels und ihre Beziehungen zu normalen und pathologischen Vorgängen. Bruns' Beiträge zur Klinischen Chirurgie, 130, 495.

Palletta, J. B. (1820): Exercitationes Pathologicae. Mediolani, 70.

Reynolds, S. R. M. (1948): Morphological Determinants of the Flow-Characteristics between an Artery and its Branch, with special reference to the Ovarian Spiral Artery in the Rabbit. Acta Anatomica, 5, 1. Richards, A. N., and Schmidt, C. F. (1924): A Description of the Glomerular Circulation in the Frog's Kidney and Observations concerning the action of Adrenaline and various other substances upon it. American Journal of Physiology, 71, 178.

Rindfleisch, G. E. (1880): Ueber Knochenmark und Blutbildung. Archiv für Mikroskopische Anatomie, $17,1$.

Sappey, Ph. C. (1869): Traité d'Anatomie Descriptive. Tome ii. Paris: Adrien Delahaye.

Trueta, J., Barclay, A. E., Daniel, P. M., Franklin, K. J., and Pritchard, M. M. L. (1947): Studies of the Renal Circulation. Oxford: Blackwell Scientific Publications Ltd.

Tucker, F. R. (1949): Arterial Supply to the Femoral Head and its Clinical Importance. Journal of Bone and Joint Surgery, 31-B, 82.

VAN Der Stricht, O. (1892): Nouvelles recherches sur la genèse des globules rouges et des globules blancs du sang. Archives de Biologie, 12, 199.

Vereby, K. (1942): Die Blutversorgung des Femurkopfes. Anatomischer Anzeiger, 93, 225

Walmsley, T. (1915): The Epiphysis of the Head of the Femur. Journal of Anatomy and Physiology, 49, 434. Wolcott, W. E. (1943): The Evolution of the Circulation in the Developing Femoral Head and Neck. Surgery, Gynecology and Obstetrics, 77, 61. 